\title{
Chapter 7 \\ Microplastics in the Marine Environment: Sources, Consequences and Solutions
}

\author{
Richard C. Thompson
}

\begin{abstract}
Microplastics are small fragments of plastic debris that have accumulated in the environment on a global scale. They originate from the direct release of particles of plastic and as a consequence of the fragmentation of larger items. Microplastics are widespread in marine habitats from the poles to the equator; from the sea surface and shoreline to the deep sea. They are ingested by a range of organisms including commercially important fish and shellfish and in some populations the incidence of ingestion is extensive. Laboratory studies indicate that ingestion could cause harmful toxicological and/or physical effects. However, our understanding of the relative importance of these effects in natural populations is very limited. Looking to the future it seems inevitable that the quantity of microplastic will increase in the environment, since even if we could stop new items of debris entering the ocean, fragmentation of the items already present would continue for years to come. The term microplastics has only been in popular usage for a decade and while many questions remain about the extent to which they could have harmful effects, the solutions to reducing this contamination are at hand. There are considerable synergies to be achieved by designing plastic items for both their lifetime in service and their efficient end-of-life recyclability, since capturing waste via recycling will reduce usage of non-renewable oil and gas used in the production of new plastics and at the same time reduce the accumulation of waste in managed facilities such as land fill as well as in the natural environment.
\end{abstract}

Keywords Microplastic • Microbeads • Accumulation • Impact • Toxicology • Solution

R.C. Thompson $(\bowtie)$

Marine Biology and Ecology Research Centre, School of Marine Science and Engineering, Plymouth University, Plymouth PL4 8AA, UK

e-mail: R.C.Thompson@plymouth.ac.uk 


\subsection{Introduction}

Microplastics is used as a collective term to describe a truly heterogeneous mixture of particles ranging in size form a few microns to several millimetres in diameter; including particles of various shapes from completely spherical to elongated fibres. Microplastics have been reported in a range of colors. However, pieces that differ in appearance according to their shape size or color to ambient natural particulates are most commonly reported, for example blue or red fibres (Hidalgo-Ruz et al. 2012). The term microplastics has been widely used in relation to anthropogenic debris since 2004 when Thompson et al. used the term to illustrate and describe the accumulation of truly microscopic pieces of plastic in marine sediments and in the water column in European waters (Fig. 7.1). Microplastic contamination has since been reported on a global scale from the poles to the equator (Barnes et al. 2009; Browne et al. 2011; Hidalgo-Ruz et al. 2012) and contaminates the water surface of the open ocean (Law et al. 2010; Collignon et al. 2012; Goldstein et al. 2012; Ivar do Sul et al. 2013), estuaries (Sadri and Thompson 2014) and lakes (Eriksen et al. 2013) together with marine (Browne et al. 2011; Santos et al. 2009) and freshwater shorelines (Imhof et al. 2013) and subtidal sediments (Browne et al. 2011) down to the deep sea (Van Cauwenberghe et al. 2013; Woodall et al. 2014). Microplastics have also been reported in considerable concentrations in Arctic sea ice (Obbard et al. 2014; Fig. 7.2). Over the past decade, interest in the topic has grown immensely and there are now well over 100 publications on microplastic (Fig. 7.3) and numerous reviews (Browne et al. 2007; Arthur et al. 2009; Andrady 2011; Cole et al. 2011; Zarfl et al. 2011; Wright et al. 2013b; Ivar do Sul and Costa 2014; Law and Thompson 2014) spanning sources, occurrence, abundance, ingestion by biota and consequences. Alongside this scientific research there has been growing interest from the media, the public and policy makers. The first policy centered workshop on the topic was hosted by NOAA in the USA during 2008 (Arthur et al. 2009). Specific reference to microplastics was later made within EU legislation via the Marine Strategy Framework Directive in 2010 (Galgani et al. 2010), and more recently there has been legislation and voluntary actions by industry to reduce the use of microplastics in cosmetics. However, even in the unlikely event that inputs of larger items of debris were to cease immediately, it is likely that the quantities of microplastics would continue to increase in the environment due to the fragmentation of legacy items of larger debris. Hence, it is essential to gain further understanding about the sources, consequences and fate of microplastics in the ocean.

Microplastics originate from a variety of sources, but these can be broadly categorized as primary: the direct release of small particles, for example, as a result of release of pellets or powders, or secondary, which results from fragmentation of larger items (Andrady 2011; Cole et al. 2011; Hidalgo-Ruz et al. 2012). Microplastic-sized particles are directly used in a wide range of applications. Plastic pellets (around $5 \mathrm{~mm}$ diameter) and powders (less than $0.5 \mathrm{~mm}$ ) are used as a feedstock for the production of larger items and the presence of these pellets (also 


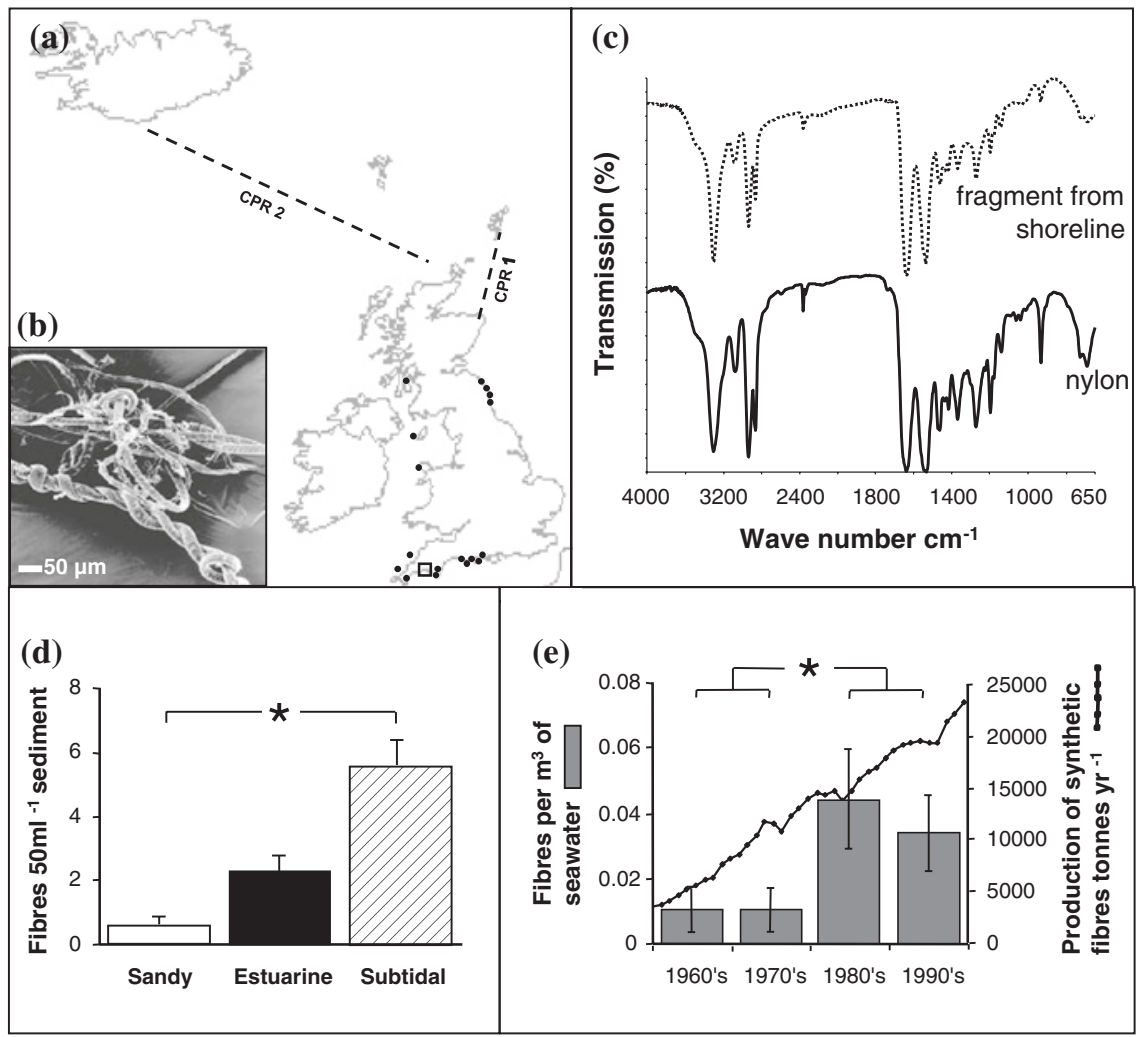

Fig. 7.1 a Sampling locations in the northeast Atlantic: six sites near Plymouth used to compare the abundance of microplastic among habitats, (open square) (see Fig. 7.1d). Other shores where similar fragments were found (black solid circles). Dashed lines show routes sampled by Continuous Plankton Recorder (CPR 1 and 2) and used to assess changes in microplastic abundance since 1960. b One of numerous fragments found among marine sediments and identified as plastic using FT-IR spectroscopy. $\mathbf{c}$ FT-IR spectra of a microscopic fragment matched that of nylon. d Microplastics were more abundant in subtidal habitats than in sandy beaches $\left(*=\mathrm{F}_{2,3}=13.26, P<0.05\right)$, but abundance was consistent among sites within habitat types. e Microscopic plastic in CPR samples revealed a significant increase in abundance when comparing the 1960s and 1970s to the 1980s and 1990s $\left(*=\mathrm{F}_{3,3}=14.42, P<0.05\right)$. Approximate global production of synthetic fibres overlain for comparison. Microplastics were also less abundant along oceanic route CPR 2 than CPR $1\left(\mathrm{~F}_{1}\right.$, $24=5.18, P<0.05$ ). Reproduced from Thompson et al. (2004) with permission

known as nurdles or mermaids tears) has been widely reported as a consequence of industrial spillage (Hays and Cormons 1974; Bourne and Imber 1982; Harper and Fowler 1987; Shiber 1987; Blight and Burger 1997). Small plastic particles typically around $0.25 \mathrm{~mm}$ are also widely used as abrasive in cosmetic products (Fig. 7.4) and as an industrial shot-blasting abrasive. Microplastics from cosmetics and cleaning agents (also known as microbeads) will be carried with waste water via sewers and are unlikely to be effectively removed by sewage treatment, and hence are accumulating in the environment (Zitko and Hanlon 1991; Gregory 


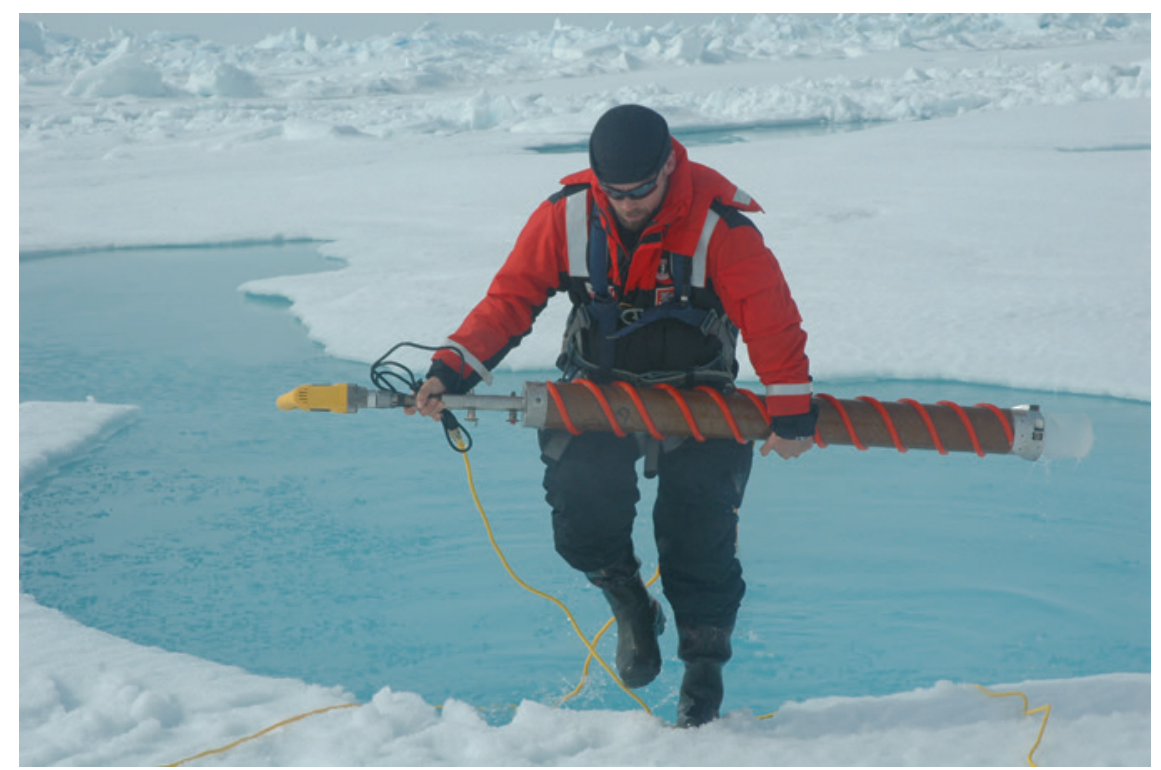

Fig. 7.2 Sea ice core being collected during the NASA ICESCAPE expedition in July 2010 (Photo: D. Perovich, U.S. Army Corps of Engineers Cold Regions Research \& Engineering)

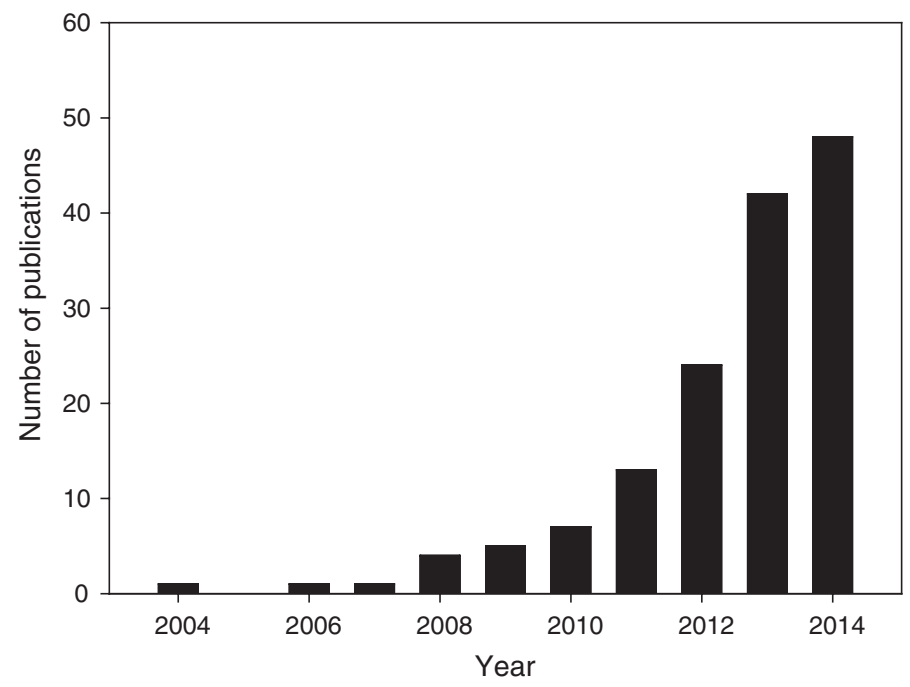

Fig. 7.3 Number of publications on microplastics over time (2004-2014). Modified from GESAMP (2014), courtesy of S. Gall, Plymouth University 


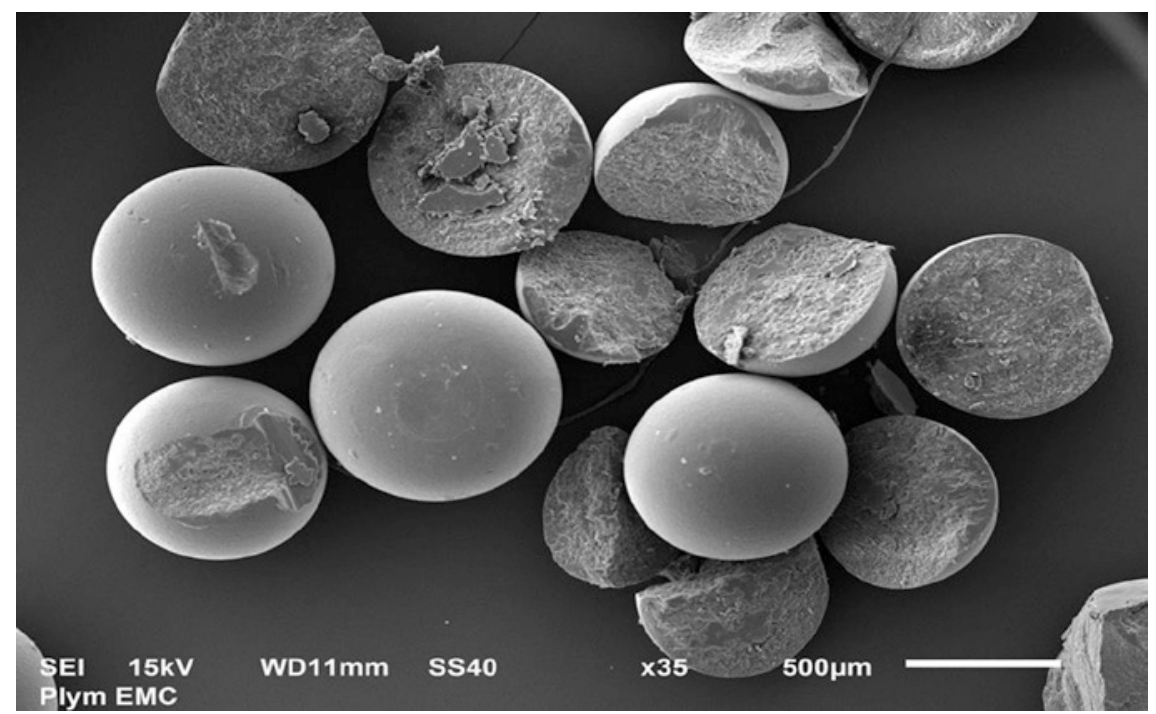

Fig. 7.4 Scanning electron microscope image of microbeads isolated from cosmetics (Photo: A. Bakir and R.C. Thompson, Plymouth University)

1996). It is estimated that in the US alone around 100 tons of microplastics might enter the oceans annually (Gouin et al. 2011). In addition to the direct release of primary microplastics, larger items of plastic debris will progressively become brittle under the action of ultraviolet light and heat and then fragment with physical action from wind and waves (Andrady 2015). Hence large items of debris are likely to represent a considerable source of microplastics (Andrady 2003, 2011). In addition to fragmentation in the environment, some items also fragment in use resulting in particles of microplastic being released to the environment as a consequence of everyday usage or cleaning. This has been demonstrated for the release of fibres from garments as a consequence of washing (Browne et al. 2011). It is now evident that, as a collective consequence of these diverse inputs, microplastics are widespread in natural habitats and in the organisms living there, including benthic invertebrates, commercially important lobsters, numerous species of fish, sea birds and marine mammals (Murray and Cowie 2011; Possatto et al. 2011; van Franeker et al. 2011; Foekema et al. 2013; Lusher et al. 2013; Rebolledo et al. 2013).

Our understanding about microplastics has advanced considerably over the last decade, but is still in its infancy and our knowledge of the relative importance of various sources, spatial trends in distribution and abundance, temporal trends, or effects on biota are still quite limited (Law and Thompson 2014). Initial work describing microplastics indicated a small increase in the abundance of this debris over time and that in laboratory conditions a range of invertebrates would ingest the material (Thompson et al. 2004). Subsequent work has described the range of habitats (Law et al. 2010; Browne et al. 2011; Van Cauwenberghe et al. 2013) and organisms (Graham and Thompson 2009; Murray and Cowie 2011; van Franeker et al. 
2011; Lusher et al. 2013) that are contaminated by microplastic in the environment. These early studies have been pioneering in nature providing proof of concept, but are difficult to use as a base line because of the inevitable lack of consistency in methods. In parallel, there have been laboratory studies which have exposed organisms to microplastics in order to determine the potential for this debris to result in harm to the creatures that encounter it in the natural environment (Browne et al. 2008, 2013; Rochman et al. 2013; Wright et al. 2013a). The main route of concern is currently as a consequence of ingestion, which could lead to physical (Wright 2014) and toxicological effects on biota (Teuten et al. 2007; Browne et al. 2008). Plastics are known to sorb persistent organic pollutants (Mato et al. 2001; Ogata et al. 2009; Teuten et al. 2009) and metals (Holmes et al. 2012) from seawater and organic pollutants can become orders of magnitude more concentrated on the surface of the plastic than in the surrounding water (Mato et al. 2001; Ogata et al. 2009; Teuten et al. 2009). There is evidence from laboratory studies that these chemicals can be transferred from plastics to organisms upon ingestion (Teuten et al. 2009) and that this can result in harm (Browne et al. 2013; Rochman et al. 2013; Wright et al. 2013a). The potential for transfer varies according to the specific combination of plastic and contaminant with some polymers such as polyethylene having considerable potential for transport (Bakir et al. 2012). Subsequent desorption will also vary according to physiological conditions upon ingestion with the presence of gut surfactants and increased temperature leading to increased desorption (Teuten et al. 2007; Bakir et al. 2012). However, modeling studies suggest that when compared to the transport of persistent organic pollutants (POPs) by other pathways such as respiration and food that plastics are not likely to be a major vector in the transport of POPs from seawater to organisms (Gouin et al. 2011; Koelmans et al. 2013). A second toxicological issue is that some plastics contain chemical additives that are potentially harmful (Rochman 2015). These additives can be present in concentrations much greater than is likely to result from sorption of POPs and there is concern that additives might be released to organisms upon ingestion (Oehlmann et al. 2009; Thompson et al. 2009; Rochman and Browne 2013). There is evidence that such chemicals can be present, for example as leachates from landfill sites, in aquatic habitats at concentrations that are sufficient to cause harm (Oehlmann et al. 2009). There is also evidence that chemical additives can transfer from plastics to sea birds (Tanaka et al. 2013). However, it is not clear whether ingestion of plastics themselves could result in sufficient transfer of additive chemicals to cause harm. This would require experiments with plastics for which the composition of chemical constituents is known.

\subsection{Definitions of Microplastics}

When reported in 2004 the term microplastics was used to describe fragments of plastic around $20 \mu \mathrm{m}$ in diameter. These were reported in intertidal and shallow subtidal sediments and in surface waters in northwestern Europe (Thompson 
et al. 2004; Fig. 7.1). Subsequent research showed that similar sized particles were present in shallow waters around Singapore ( $\mathrm{Ng}$ and Obbard 2006). However, while these early reports referred to truly microscopic particles they did not give a specific definition of microplastic. In 2008, the National Oceanographic and Atmospheric Agency (NOAA) of the US hosted the first International Microplastics Workshop in Washington and as part of this meeting formulated a broader working definition to include all particles less than $5 \mathrm{~mm}$ in diameter (Arthur et al. 2009). Particles of this size (i.e. $<5 \mathrm{~mm}$ ) have been very widely reported including publications that considerably pre-dated the use of the term "microplastics" (Carpenter et al. 1972; Colton et al. 1974). There is still some debate over the most appropriate upper size bound to use in a formal definition of microplastics, with perhaps a more intuitive boundary following the SI classification of $<1 \mathrm{~mm}$. The European Union have followed the US and adopted a 5-mm upper bound for categorization of microplastics within the Marine Strategy Framework Directive (MSFD, Galgani et al. 2010). There is a similar lack of clarity when considering the lower size bound for a definition of microplastics. Operationally, this, by default, has been assumed to be the mesh size of the particular net or sieve used to separate the microplastic from the bulk medium of sediment or water column (see review by Hidalgo-Ruz et al. 2012). However, as a necessity of construction, collection devices with meshes in the sub-millimetre size range have a high ratio of net/sieve material compared to apertures and as a consequence they will trap particles much smaller than the size of the apertures/mesh size. Hence, it is not sensible to define the minimum size captured on the basis of the mesh used to collect the sample. Within the EU MSFD a pragmatic approach has been taken based on that used by researchers sampling benthic infauna and sediments with sieves (e.g. Wentworth graduated sieves), where the organisms 'retained' by a particular sieve are reported. In summary, there is no universally agreed definition of microplastic size, but most workers consider microplastic to be particles of plastic $<5 \mathrm{~mm}$ in size. There is little consensus on the lower size bound.

While defining parameters is essential for consistent monitoring, in the wider context of marine debris and concerns about the potential harmful effects of microplastic it may actually be unwise to specify the size definitions precisely at the present time. Differently sized particles are likely to have differing effects. For example, smaller particles could have consequences that are fundamentally different to larger particles, since the particles themselves can accumulate in tissues and/ or may cause disruption of physiological processes (Browne et al. 2008; Wright et al. 2013c). From a monitoring science, rather than a curiosity-driven perspective, a logical rationale for sampling is to consider abundance in relation to any associated impacts. Since our understanding of the potential impacts of microplastics is currently in its infancy it could, for the time being, be unwise to set a formal limit to lower size boundary and, until there is better understanding about which types/sizes of microplastics are of concern a sensible strategy could be to collect from the bulk medium any particles $<5 \mathrm{~mm}$ and then quantify microplastics according to size categories. 


\subsection{Spatial and Temporal Patterns in the Abundance of Microplastics}

Our understanding about the distribution and the factors affecting the distribution of microplastics in the oceans is limited and much of the sampling to date has been opportunistic utilizing existing research programs (research cruises, educational programs, routine plankton monitoring) to collect material. There has also been some targeted microplastic sampling and attempts to make formal comparisons in the abundance of microplastics between locations (Browne et al. 2010, 2011). Existing data indicate that microplastics are widely distributed in surface waters, in shallow waters (Browne et al. 2011; Hidalgo-Ruz et al. 2012), in deepsea sediments (Van Cauwenberghe et al. 2013) and in the digestive tract of a range of organisms living within these habitats (Lusher 2015). With the exception of heavily contaminated areas such as shipbreaking yards (Reddy et al. 2006), the abundance of microplastics would appear to be relatively low in surface waters and sediments (see Lusher 2015). By volume it is apparent, however, that sediments are more contaminated than surface waters.

However, because of their ubiquity, the total quantity of microplastics in the environment is considerable and in some locations represents the most numerous type of debris present (Browne et al. 2010). This ubiquity is also demonstrated by encounters when considered by marine species, of which around $10 \%$ are with microplastics (Secretariat of the Convention on Biological Diversity and Scientific and Technical Advisory Panel GEF 2012). In terms of spatial patterns in abundance, at a global scale Browne et al. (2011) detected a weak relationship between the abundance of microplastics and human population density. Extensive sampling by Law et al. (2010) demonstrated the role of large-scale physical factors leading to increased abundance in the North Atlantic gyre far from the nearest land. She matched abundance data form the ocean surface with model predictions based on physical factors indicating that, at large scales, factors driving the abundance of debris can be used to make predictions about relative abundance (Law et al. 2010; Fig. 7.5). Formal comparisons also demonstrated patterns at smaller spatial scales with locations previously used for the dumping of sewage sludge having greater quantities of microplastic than control areas (Browne et al. 2011). In addition, intertidal sediments on shores that were downwind in relation to prevailing wind direction can have greater quantities of microplastic than those on shorelines that were up-wind (Browne et al. 2010). Targeted sampling has also indicated extremely high microplastic abundance near to a plastic processing plant in Sweden (Norén 2008). However, while the role of some potential sources including sewage and industrial spillage have been demonstrated together with the influence of physical factors leading to accumulation of debris in particular locations, our collective understanding of the relative importance of these factors in influencing spatial patterns of distribution or in making predictions about such is limited.

Only a handful of studies have considered temporal patterns in the abundance of microplastics. Thompson et al. (2004) in the northeast Atlantic and Goldstein 


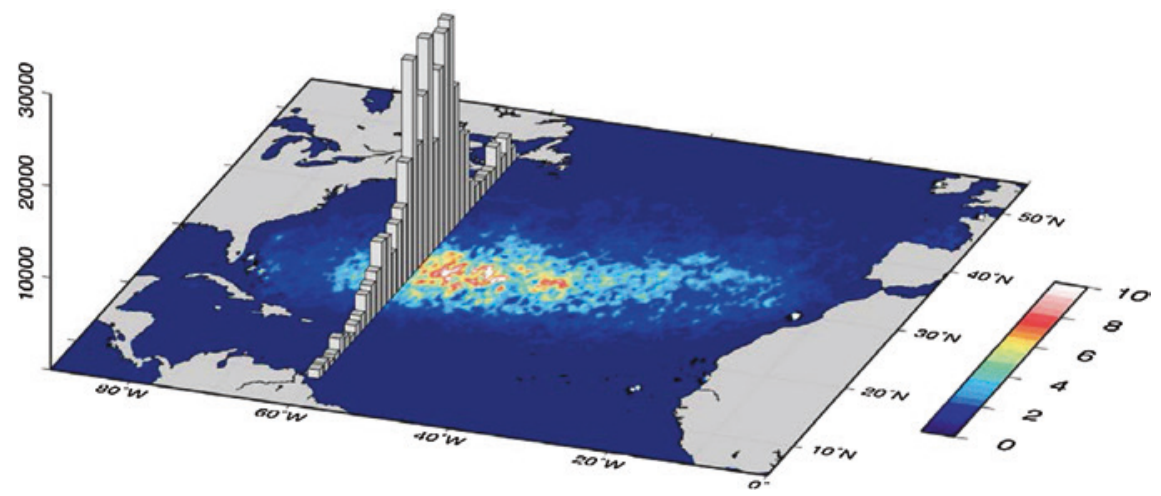

Fig. 7.5 Average plastic concentration as a function of latitude (bars, units of pieces $\mathrm{km}^{-2}$ ), and concentration, $\mathrm{C}$ (color shading), of initially homogeneous $(\mathrm{C}=1$ ) surface tracer after 10-year model integration. Averages and standard errors were computed in one-degree latitude bins. The highest plastic concentrations were observed in subtropical latitudes $\left(22-38^{\circ} \mathrm{N}\right)$ where model tracer concentration is also a maximum. Reproduced from Law et al. (2010) with permission

et al. (2012) in the North Pacific both report on an increase in abundance over time. While examination of a very extensive data set by Law et al. (2010) revealed no clear temporal trend in abundance over two decades of sampling in the North Atlantic, Thompson et al. (2004) used samples collected by the continuous plankton recorder to examine temporal changes in surface waters to the north of Scotland and showed a significant increase in the abundance of microplastics when comparing between the 1960s and 1970s with the 1980s and 1990s. Goldstein et al. (2012) compared abundance in heavily contaminated areas of the Pacific and also recorded and increase in abundance over time. However, sampling methodology differed between sampling dates making it difficult to clearly identify the underlying trends in microplastic abundance (Goldstein et al. 2012). It is clear that the abundance of microplastic is likely to vary considerably in space and in time, but we have little understanding of the associated scales of variation, neither do we have a clear understanding about the relative importance of, or interactions among, the various factors affecting distribution or about which, if any, types of microplastic might be hazardous. Such uncertainty considerably limits our ability to implement monitoring programs necessary to assess changes in abundance over time and in relation to regulatory measures.

\subsection{Anticipated Future Trends}

Global production of plastic has increased from around 5 million tons per year during the 1950s to over 280 million tons today (Thompson et al. 2009; PlasticsEurope 2011). However, the majority of this is used to make single-use items, which are disposed of within a year of production (Thompson et al. 2009). 
Hence, considerable quantities of end-of-life plastics are accumulating in land fills and in the natural environment. The quantity of end-of-life plastic in the marine environment is substantial but as yet there are few reliable estimates of the total amount, or the relative proportions of different types of debris such as microplastic. Recent studies have attempted to assess global distributions (Cózar et al. 2014; Eriksen et al. 2014), the logical next step could be to estimate total production, current tonnage in use and accumulated disposal via recognized waste management in order to establish via a mass balance the amount of plastic that is missing and potentially in the environment (Jambeck et al. 2015). It is apparent that end-of-life plastic items are abundant and widely distributed in the oceans and that these items are progressively fragmenting into small pieces which are now abundant in the environment (Fig. 7.6). In some locations, it is evident that microplastics are numerically, as opposed to by mass, the most abundant type of solid debris present (Browne et al. 2010). However, despite the deterioration of plastic items into plastic fragments, conventional plastics will not readily biodegrade and it is considered that all of the plastics that have ever been produced are still present

Fig. 7.6 Accumulation of plastic debris on a shoreline in Europe. Small fragments of plastic including microplastics pieces $<5 \mathrm{~mm}$ are often overlooked during routine beach monitoring, but are now the most abundant items on many shorelines (Photo: R.C. Thompson)

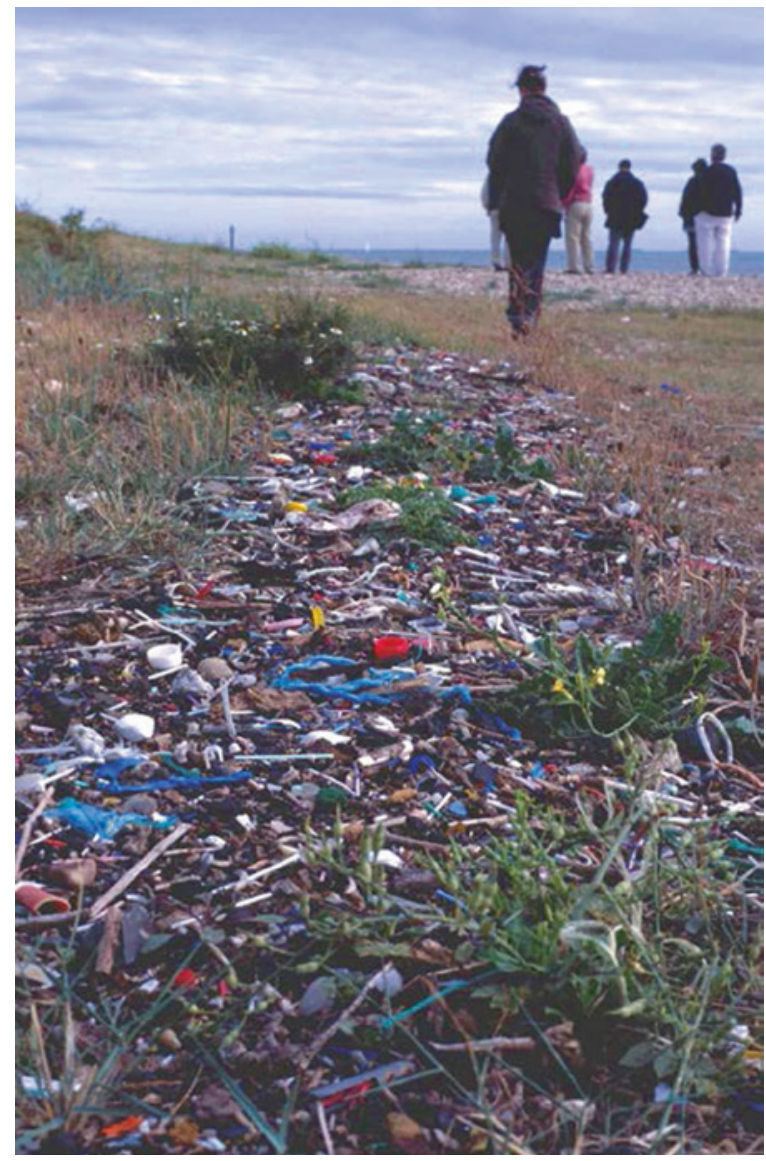


on the planet (unless they have bene incinerated) (Thompson et al. 2005). Hence, even if we were to cease using plastic items, which is not something I would advocate, the quantity of microplastic will continue to increase as a consequence of fragmentation of existing larger items (Thompson et al. 2009; STAP 2011).

From a personal perspective my interest in what we now describe as microplastics started in the in the mid-1990s. I was well aware that over the previous decades we had shifted to a very disposable society with considerable generation of waste. It was apparent that waste items including plastics were entering the oceans on a daily basis. These plastic items were resistant to degradation and I became curious as to where all the end-of-life single-use plastic items were accumulating in the natural environment. At that time, as is still largely the case, there was a distinct lack of data indicating any increasing temporal trends in the abundance of plastic debris and I considered that a substantial proportion may be accumulating as fragments, which were being missed by routine litter surveys (Fig. 7.6). These observations inspired the research leading to my paper in 2004 entitled 'Lost at sea where is all the plastic?'. In this paper I suggested that one reason we were not seeing a temporal trend was because the smaller fragments that were forming from larger items were not being recorded in routine monitoring. Ten years on it seems likely that accumulation of microplastics represents an important sink where the fragments of larger items reside in a size range that has seldom been monitored. However, while widely distributed in the marine environment the densities of microplastic recorded in the habitats studied to date are relatively low and indicate that if microplastics are indeed the ultimate end-product of our disposable society then some of the major sinks of this material are yet to be discovered. Many consider the deep sea likely to be a major sink and there is growing evidence that substantial quantities of macroplastic are accumulating there (Galgani et al. 1996). An initial survey suggested abundance in the deep sea may be lower than in shallow water habitats (Van Cauwenberghe et al. 2013), however using different approaches to record fibres there is recent evidence that the deep sea could be a substantial sink for microplastics (Woodall et al. 2014). Clearly more investigation is required to confirm the relative importance of the deep sea as a sink for microplastics, to understand their long-term fate in the deep sea and the extent of any subsequent deterioration or biodegradation over extended timescales (Zettler et al. 2013).

\subsection{Conclusions}

It is evident that microplastic pieces now contaminate marine habitats worldwide. This debris is ingested by a wide range of organisms and for some species a major proportion of the population contains plastic fragments. There are concerns about the physical and toxicological harm that ingesting this debris might cause and laboratory experiments have demonstrated harmful effects. However, the relative importance of plastics as a vector for chemical transport or their importance as 
an agent causing physical harm to organisms in the natural environment are much less clear (Koelmans 2015).

Our understanding of potential future trends in the abundance of microplastic debris is limited. While it seems inevitable that the quantities of microplastic will increase in the environment as a consequence of further direct introductions of primary microplastic and fragmentation of larger items the likely trajectories and potential sinks or hot spots of accumulation are not clear. In conclusion, 10 years after the term microplastic widely entered the published literature and after a considerable body of research, there remain more questions than answers about the accumulation and consequences of microplastic contamination in the environment (Law and Thompson 2014). Ultimately, however, there is broad recognition that plastic debris does not belong in the ocean. It is also clear that the numerous societal benefits that are derived from every-day-use of plastics can be achieved without the need for emissions of plastic waste to the environment. Since $8 \%$ of the global oil production is currently used to make plastic items it seems clear that we urgently need to change the way we produce, use and dispose of plastic items. There is also a growing realization that the solution to two major environmental problems, our non-sustainable use of fossil carbon and accumulation of debris lie in utilizing end-of-life plastics as a raw material for new production. Such principles are central to the philosophy of developing a more circular economy and some believe that rethinking our use of plastic materials in line with this philosophy has considerable potential to bring much greater resource efficiency (European Commission 2012).

Open Access This chapter is distributed under the terms of the Creative Commons Attribution Noncommercial License, which permits any noncommercial use, distribution, and reproduction in any medium, provided the original author(s) and source are credited.

\section{References}

Andrady, A. L. (Ed.). (2003). Plastics in the environment. Plastics in the Environment. New Jersey: Wiley.

Andrady, A. L. (2011). Microplastics in the marine environment. Marine Pollution Bulletin, 62, $1596-1605$.

Andrady, A. L. (2015). Persistence of plastic litter in the oceans. In M. Bergmann., L. Gutow, M. Klages (Eds.), Marine anthropogenic litter (pp. 57-72). Berlin: Springer.

Arthur, C., Baker, J., \& Bamford, H. (2009). Proceedings of the international research workshop on the occurrence, effects and fate of microplastic marine debris. Sept 9-11, 2008, NOAA Technical Memorandum NOS-OR\&R30.

Bakir, A., Rowland, S. J., \& Thompson, R. C. (2012). Competitive sorption of persistent organic pollutants onto microplastics in the marine environment. Marine Pollution Bulletin, 64, 2782-2789.

Barnes, D. K. A., Galgani, F., Thompson, R. C., \& Barlaz, M. (2009). Accumulation and fragmentation of plastic debris in global environments. Philosophical Transactions of the Royal Society B, 364, 1985-1998.

Blight, L. K., \& Burger, A. E. (1997). Occurrence of plastic particles in seabirds from the eastern North Pacific. Marine Pollution Bulletin, 34, 323-325. 
Bourne, W. R. P., \& Imber, M. J. (1982). Plastic pellets collected by a prion on Gough Island, Central South-Atlantic ocean. Marine Pollution Bulletin, 13, 20-21.

Browne, M. A., Galloway, T. S., \& Thompson, R. C. (2007). Microplastic-An emerging contaminant of potential concern. Integrated Environmental Assessment and Management, 3, 559-566.

Browne, M. A., Dissanayake, A., Galloway, T. S., Lowe, D. M., \& Thompson, R. C. (2008). Ingested microscopic plastic translocates to the circulatory system of the mussel, Mytilus edulis (L.). Environmental Science and Technology, 42, 5026-5031.

Browne, M. A., Galloway, T. S., \& Thompson, R. C. (2010). Spatial patterns of plastic debris along estuarine shorelines. Environmental Science and Technology, 44, 3404-3409.

Browne, M. A., Crump, P., Niven, S. J., Teuten, E., Tonkin, A., Galloway, T. S., et al. (2011). Accumulation of microplastic on shorelines woldwide: Sources and sinks. Environmental Science and Technology, 45, 9175-9179.

Browne, M. A., Niven, S. J., Galloway, T. S., Rowland, S. J., \& Thompson, R. C. (2013). Microplastic moves pollutants and additives to worms, reducing functions linked to health and biodiversity. Current Biology, 23, 2388-2392.

Carpenter, E. J., Anderson, S. J., Harvey, G. R., Miklas, H. P., \& Bradford, B. P. (1972). Polystyrene spherules in coastal waters. Science, 178, 749-750.

Cole, M., Lindeque, P., Halsband, C., \& Galloway, T. S. (2011). Microplastics as contaminants in the marine environment: A review. Marine Pollution Bulletin, 62, 2588-2597.

Collignon, A., Hecq, J. H., Galgani, F., Voisin, P., Collard, F., \& Goffart, A. (2012). Neustonic microplastic and zooplankton in the North Western Mediterranean Sea. Marine Pollution Bulletin, 64, 861-864.

Colton, J. B., Knapp, F. D., \& Burns, B. R. (1974). Plastic particles in surface waters of the Northwestern Atlantic. Science, 185, 491-497.

Cózar, A., Echevarria, F., Gonzalez-Gordillo, J. I., Irigoien, X., Ubeda, B., Hernandez-Leon, S., et al. (2014). Plastic debris in the open ocean. Proceedings of the National Academy of Sciences of the United States of America, 111, 10239-10244.

Eriksen, M., Mason, S., Wilson, S., Box, C., Zellers, A., Edwards, W., et al. (2013). Microplastic pollution in the surface waters of the Laurentian Great Lakes. Marine Pollution Bulletin, 77, 177-182.

Eriksen, M., Lebreton, L. C. M., Carson, H. S., Thiel, M., Moore, C. J., Borerro, J. C., et al. (2014). Plastic pollution in the world's oceans: more than 5 trillion plastic pieces weighing over 250,000 tons afloat at sea. PLoS ONE, 9, 111913.

European Commission. (2012). Manifesto for a resource-efficient Europe, p. 2. Brussels.

Foekema, E. M., De Gruijter, C., Mergia, M. T., van Franeker, J. A., Murk, A. J., \& Koelmans, A. A. (2013). Plastic in North sea fish. Environmental Science and Technology, 47, 8818-8824.

Galgani, F., Fleet, D., Van Franeker, J., Katsanevakis, S., Maes, T., Mouat, J., et al. (2010). Marine strategy framework directive, task group 10 report: Marine litter. In N. Zampoukas (Ed.), JRC scientific and technical reports. Ispra: European Comission Joint Research Centre.

Galgani, F., Souplet, A., \& Cadiou, Y. (1996). Accumulation of debris on the deep sea floor off the French Mediterranean coast. Marine Ecology Progress Series, 142, 225-234.

Goldstein, M., Rosenberg, M., \& Cheng, L. (2012). Increased oceanic microplastic debris enhances oviposition in an endemic pelagic insect. Biology Letters, 11, doi: 10.1098/rsbl.2012.0298.

Gouin, T., Roche, N., Lohmann, R., \& Hodges, G. (2011). A thermodynamic approach for assessing the environmental exposure of chemicals absorbed to microplastic. Environmental Science and Technology, 45, 1466-1472.

Graham, E. R., \& Thompson, J. T. (2009). Deposit- and suspension-feeding sea cucumbers (Echinodermata) ingest plastic fragments. Journal of Experimental Marine Biology and Ecology, 368, 22-29.

Gregory, M. R. (1996). Plastic 'scrubbers' in hand cleansers: A further (and minor) source for marine pollution identified. Marine Pollution Bulletin, 32, 867-871.

Harper, P. C., \& Fowler, J. A. (1987). Plastic pellets in New Zealand storm-killed prions (Pachyptila spp.), 1958-1998. Notornis, 34, 65-70. 
Hays, H., \& Cormons, G. (1974). Plastic particles found in tern pellets, on coastal beaches and at factory sites. Marine Pollution Bulletin, 5, 44-46.

Hidalgo-Ruz, V., Gutow, L., Thompson, R. C., \& Thiel, M. (2012). Microplastics in the marine environment: A review of the methods used for identification and quantification. Environmental Science and Technology, 46, 3060-3075.

Holmes, L. A., Turner, A., \& Thompson, R. C. (2012). Adsorption of trace metals to plastic resin pellets in the marine environment. Environmental Pollution, 160, 42-48.

Imhof, H. K., Ivleva, N. P., Schmid, J., Niessner, R., \& Laforsch, C. (2013). Contamination of beach sediments of a subalpine lake with microplastic particles. Current Biology, 23, R867-R868.

Ivar do Sul, J. A., \& Costa, M. F. (2014). The present and future of microplastic pollution in the marine environment. Environmental Pollution, 185, 352-364.

Ivar do Sul, J. A., Costa, M. F., Barletta, M., \& Cysneiros, F. J. A. (2013). Pelagic microplastics around an archipelago of the equatorial Atlantic. Marine Pollution Bulletin, 75, 305-309.

Jambeck J. R., Geyer, R., Wilcox, C., Siegler, T. R , Perryman, M., Andrady, A., et al. (2015). Plastic waste inputs from land into the ocean. Science, 347, 6223, 768-771.

Koelmans, A. A. (2015). Modeling the role of microplastics in bioaccumulation of organic chemicals to marine aquatic organisms. Critical review. In M. Bergmann., L. Gutow., \& M. Klages (Eds.), Marine anthropogenic litter (pp. 313-328). Berlin: Springer.

Koelmans, A. A., Besseling, E., Wegner, A., \& Foekema, E. M. (2013). Plastic as a carrier of POPs to aquatic organisms: A model analysis. Environmental Science and Technology, 47, 7812-7820.

Law, K. L., \& Thompson, R. C. (2014). Microplastics in the seas. Science, 345, 144-145.

Law, K. L., Morét-Ferguson, S., Maximenko, N. A., Proskurowski, G., Peacock, E. E., Hafner, J., et al. (2010). Plastic accumulation in the North Atlantic subtropical gyre. Science, 329, $1185-1188$.

Lusher, A. (2015). Microplastics in the marine environment: distribution, interactions and effects. In M. Bergmann., L. Gutow., \& M. Klages (Eds.), Marine anthropogenic litter (pp. 245-308). Berlin: Springer.

Lusher, A., McHugh, M., \& Thompson, R. C. (2013). Occurrence of microplastics in the gastrointestinal tract of pelagic and demersal fish from the English Channel. Marine Pollution Bulletin, 67, 94-99.

Mato, Y., Isobe, T., Takada, H., Kanehiro, H., Ohtake, C., \& Kaminuma, T. (2001). Plastic resin pellets as a transport medium for toxic chemicals in the marine environment. Environmental Science and Technology, 35, 318-324.

Murray, F., \& Cowie, P. R. (2011). Plastic contamination in the decapod crustacean Nephrops norvegicus (Linnaeus, 1758). Marine Pollution Bulletin, 62, 1207-1217.

Ng, K. L., \& Obbard, J. P. (2006). Prevalence of microplastics in Singapore's coastal marine environment. Marine Pollution Bulletin, 52, 761-767.

Norén, F. (2008). Small plastic particles in coastal Swedish waters (p. 11). Lysekil: KIMO Sweden.

Obbard, R. W., Sadri, S., Wong, Y. Q., Khitun, A. A., Baker, I. \& Thompson, R. C. (2014). Global warming releases microplastic legacy frozen in Arctic Sea ice. Earth's Future, 2, 315-320.

Oehlmann, J., Schulte-Oehlmann, U., Kloas, W., Jagnytsch, O., Lutz, I., Kusk, K. O., et al. (2009). A critical analysis of the biological impacts of plasticizers on wildlife. Philosophical Transactions of the Royal Society B, 364, 2047-2062.

Ogata, Y., Takada, H., Master, M. K., Hirai, H., Iwasa, S., Endo, S., et al. (2009). International pellet watch: Global monitoring of persistent organic pollutants (POPs) in coastal waters. 1. Initial phase data on PCBs, DDTs, and HCHs. Marine Pollution Bulletin, 58, 1437-1466.

PlasticsEurope. (2011). Plastics the facts 2011. An analysis of European plastics production, demand and recovery for 2010, PlasticsEurope, p. 32.

Possatto, F. E., Barletta, M., Costa, M. F., do Sul, J. A. I., \& Dantas, D. V. (2011). Plastic debris ingestion by marine catfish: An unexpected fisheries impact. Marine Pollution Bulletin, 62, 1098-1102. 
Rebolledo, E. L. B., Van Franeker, J. A., Jansen, O. E., \& Brasseur, S. M. J. M. (2013). Plastic ingestion by harbour seals (Phoca vitulina) in The Netherlands. Marine Pollution Bulletin, 67, 200-202.

Reddy, M. S., Basha, S., Adimurthy, S., \& Ramachandraiah, G. (2006). Description of the small plastics fragments in marine sediments along the Alang-Sosiya ship-breaking yard, India. Estuarine, Coastal and Shelf Science, 68, 656-660.

Rochman, C. M. (2015). The complex mixture, fate and toxicity of chemicals associated with plastic debris in the marine environment. In M. Bergmann., L. Gutow., \& M. Klages (Eds.), Marine anthropogenic litter (pp. 117-140). Berlin: Springer.

Rochman, C. M., \& Browne, M. A. (2013). Classify plastic waste as hazardous. Nature, 494, 169-171.

Rochman, C. M., Hoh, E., Kurobe, T., \& Teh, S. J. (2013). Ingested plastic transfers hazardous chemicals to fish and induces hepatic stress. Nature Scientific Reports, 3, 3263.

Sadri, S. S., \& Thompson, R. C. (2014). On the quantity and composition of floating plastic debris entering and leaving the Tamar Estuary, Southwest England. Marine Pollution Bulletin, 81, 55-60.

Santos, I. R., Friedrich, A., \& do Sul, J. A. I. (2009). Marine debris contamination along undeveloped tropical beaches from northeast Brazil. Environmental Monitoring and Assessment, 148, $455-462$.

Secretariat of the Convention on Biological Diversity and Scientific and Technical Advisory Panel GEF. (2012). Impacts of marine debris on biodiversity: Current status and potential solutions (Vol. 67, p. 61). Montreal.

Shiber, J. G. (1987). Plastic pellets and tar on spain mediterranean beaches. Marine Pollution Bulletin, 18, 84-86.

STAP. (2011). Marine debris as a global environmental problem: Introducing a solutions based framework focused on plastic. In a STAP information document (p. 40). Washington, DC: Global Environment Facility.

Tanaka, K., Takada, H., Yamashita, R., Mizukawa, K., Fukuwaka, M., \& Watanuki, Y. (2013). Accumulation of plastic-derived chemicals in tissues of seabirds ingesting marine plastics. Marine Pollution Bulletin, 69, 219-222.

Teuten, E. L., Rowland, S. J., Galloway, T. S., \& Thompson, R. C. (2007). Potential for plastics to transport hydrophobic contaminants. Environmental Science and Technology, 41, 7759-7764.

Teuten, E. L., Saquing, J. M., Knappe, D. R. U., Barlaz, M. A., Jonsson, S., Björn, A., et al. (2009). Transport and release of chemicals from plastics to the environment and to wildlife. Philosophical Transactions of the Royal Society B, 364, 2027-2045.

Thompson, R. C., Olsen, Y., Mitchell, R. P., Davis, A., Rowland, S. J., John, A. W. G., et al. (2004). Lost at sea: Where is all the plastic? Science, 304, 838.

Thompson, R. C., Moore, C., Andrady, A., Gregory, M., Takada, H., \& Weisberg, S. (2005). New directions in plastic debris. Science, 310, 1117.

Thompson, R. C., Moore, C., vom Saal, F. S., \& Swan, S. H. (2009). Plastics, the environment and human health: Current consensus and future trends. Philosophical Transactions of the Royal Society B, 364, 2153-2166.

Van Cauwenberghe, L., Vanreusel, A., Mees, J., \& Janssen, C. R. (2013). Microplastic pollution in deep-sea sediments. Environmental Pollution (Barking, Essex: 1987), 182, 495-499.

van Franeker, J. A., Blaize, C., Danielsen, J., Fairclough, K., Gollan, J., Guse, N., et al. (2011). Monitoring plastic ingestion by the northern fulmar Fulmarus glacialis in the North Sea. Environmental Pollution, 159, 2609-2615.

Woodall, L. C., Sanchez-Vidal, A., Canals, M., Paterson, G. L. J., Coppock, R., Sleight, V., et al. (2014). The deep sea is a major sink for microplastic debris. Royal Society Open Science 1, 140317.

Wright, S. L., Rowe, D., Thompson, R. C., \& Galloway, T. S. (2013a). Microplastic ingestion decreases energy reserves in marine worms. Current Biology, 23, 1031-1033. 
Wright, S. L., Thompson, R. C., \& Galloway, T. S. (2013b). The physical impacts of microplastics on marine organisms: A review. Environmental Pollution, 178, 483-492.

Wright, S. L., Rowe, D. Thompson, R. C. \& Galloway T. S. (2014). Microplastic ingestion decreases energy reserves in marine worms. Current Biology, 23, R1031-R1033.

Zarfl, C., Fleet, D., Fries, E., Galgani, F., Gerdts, G., Hanke, G., et al. (2011). Microplastics in oceans. Marine Pollution Bulletin, 62, 1589-1591.

Zettler, E. R., Mincer, T. J., \& Amaral-Zettler, L. A. (2013). Life in the "Plastisphere": Microbial communities on plastic marine debris. Environmental Science and Technology, 47, 7137-7146.

Zitko, V., \& Hanlon, M. (1991). Another source of pollution by plastics-Skin cleaners with plastic scrubbers. Marine Pollution Bulletin, 22, 41-42. 